\title{
Anatomia da desumanização
}

\author{
Maria Helena Serôdio
}
Um homem é um homem,
de Bertolt Brecht,
enc. Luis Miguel Cintra,
Teatro da Cornucópia,
2005 (José Wallenstein,
Maria João Luis,
Dinarte Branco,
Ricardo Aibéo,
Nuno Lopes e
Duarte Guimarães),
fot. Luis Santos.

Na 1. ${ }^{a}$ versão da peça

Um homem éum homem, de 1927, este "drama cómico" figurava como "apêndice" ou "epilogo". Em versões posteriores cai este outro texto, mas será recuperado na versão de 1953 com outra forma de enquadramento para que aponta o subtitulo "Um interlúdio para o foyer".

${ }^{2}$ V. Maria Manuela Gouveia Delille (Org.),

Do pobre B.B. em Portugal: Aspectos da recepção de Bertolt Brecht antes e depois do 25 de Abril de 1974, Aveiro, Editora Estante, 1991, pp. 27-58.

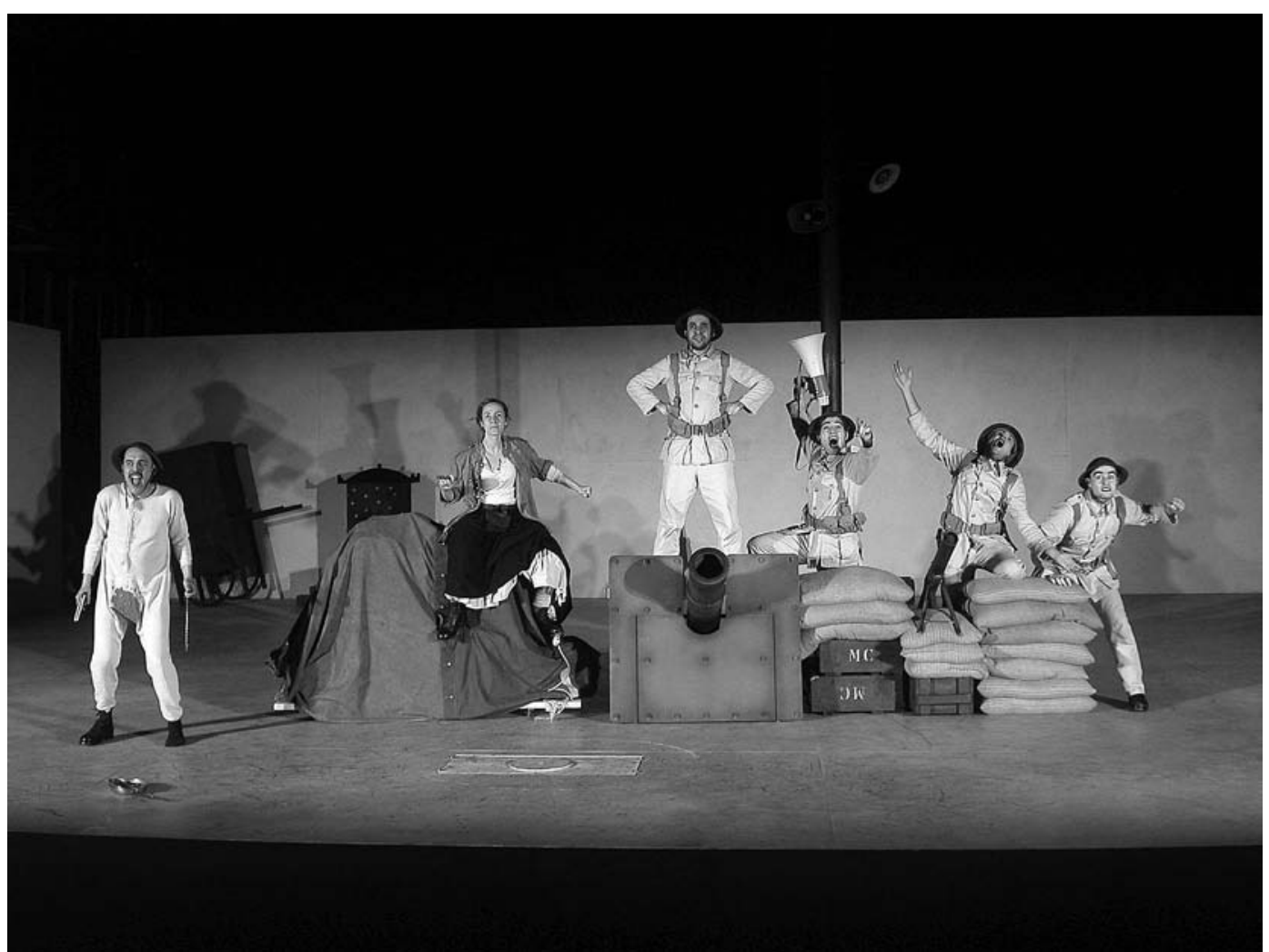

Titulo: Um homem é um homem (1953; o espectáculo integra também o entremez A cria de elefante, de 1927'). Autor: Bertolt Brecht. Tradução: António Conde (Um homem é um homem) e José Maria Vieira Mendes (A cria de elefante). Encenação: Luis Miguel Cintra. Cenários e figurinos: Cristina Reis. Desenho de luzes: Daniel Worm d'Assumpção. Colaboração musical: João Paulo Santos. Som: Vasco Pimentel e Hugo Reis. Interpretação: Cláudia Jardim, Dinarte Branco, Duarte Guimarães, Henrique Cardador, João Lizardo, José Wallenstein, Luís Lima Barreto, Maria João Luis, Ricardo Aibéo, Nuno Lopes, Pedro Lacerda, Tiago Matias. Pianista: Nuno Lopes. Produção: Teatro da Cornucópia. Local e data de estreia: Teatro do Bairro Alto, Lisboa, 7 de Abril de 2005.

Nem sempre é fácil detectar momentos de fractura ou superação no campo da arte, sobretudo quando o tecido artístico parece fragmentar-se e as suas intervenções se revelam algo dispersas e efémeras, como acontece com o teatro. Por outro lado, a visibilidade de alguns desses aspectos pode ficar prejudicada por focalizações diversas que os meios de comunicação, a publicidade, ou mesmo modismos vários vão favorecendo de forma incerta ou menos oportuna. A verdade, porém, é que o fenómeno Brecht eclodiu entre nós neste início do século XXI de uma forma tão consistente e tão elaborada que necessariamente aponta para uma superação na sua abordagem e mesmo na sua reinvenção cénica.

Todavia, tal não seria possivel se não houvesse já, em Portugal, um historial de progressivo domínio da sua obra e pensamento no último quartel do século passado. Tinham saído a lume, mesmo antes disso, as traduções que a Portugália Editora, entre 1962 e 1970, foi sistematicamente editando: cinco volumes do Teatro de Brecht (em traduções de Ilse Losa, Yvette Centeno e Fiama Hasse Pais Brandão, com a colaboração de Jorge de Sena ou Alexandre O'Neill, nos poemas), a que se acrescentou em 1975 um 6. ${ }^{\circ}$ volume. Mas, apesar da sua enorme importância, o projecto não chegou a cumprir a intenção inicial de dar a obra completa de Brecht. Todavia, é justo ainda realçar que a mesma editora resolvia iniciar uma colecção Problemas, dando à estampa em 1964 Os estudos sobre teatro, de Brecht, com tradução de Fiama Hasse Pais Brandão, volume que foi decisivo para o conhecimento do seu pensamento (já que a prática era ainda interdita entre nós ${ }^{2}$ ). Ainda assim, aos textos do autor, entretanto acessiveis, dever-se-ão acrescentar os vários estudos e artigos dispersos, que 
foram sendo publicados, e que Maria Manuela Gouveia Delille ${ }^{3}$ tem vindo a inventariar de forma atenta: os de dramaturgistas (de que se destaca Vera San Payo de Lemos), críticos (como Carlos Porto e Mário Sério), estudiosos e ensaistas de teatro (proeminente, entre eles, Luiz Francisco Rebello, com o volume Teatro moderno, de 1957 e 1964), entre outros.

Houve ainda, é certo, os espectáculos dos que nos têm vindo visitar, e de que recordo dois exemplos recentes, apaixonantes, ambos apresentados no Centro Cultural de Belém: A resistivel ascensão de Arturo Ui, pelo Berliner Ensemble, seguindo a encenação de Heiner Müller (2 de Setembro de 1997) e 0 círculo de giz caucasiano, pelo Teatro Stabile del Veneto, encenado por Benno Besson (no âmbito do Festival de Almada, a 16 de Junho de 2003). Mas recordo aqui também construções feitas em palco por portugueses: encenadores como João Lourenço, Jorge Silva Melo, Luís Varela, Carlos Avilez, João Mota, Joaquim Benite, Mário Barradas, Artur Ramos, Fernando Gusmão, José Peixoto, Hélder Costa, José Caldas, João Perry, Rui Madeira, Armando Caldas e Pedro Wilson ${ }^{4}$, entre outros, foram exercitando modos de argumentação artística, maneiras de inventar imagens e sequências, bem como rumos e falas, que tornaram Brecht um autor conhecido, entre nós, embora não pacífico. E isso não só porque se estaria ou não de acordo com o texto ou com o espectáculo, mas antes porque com Brecht a impugnação do conhecido e do "natural" é força de arte, e porque não têm sido politicamente isentas de polémica a sua memória, a sua recepção e a sua herança. De resto, também a nível internacional, e mesmo fora do debate mais estritamente político, ou assumidamente estético, bastaria confrontar - para o recorte humano -, por um lado, o depoimento belíssimo de um exigente criador como Giorgio Strehler (1980: 92-110), que se deslumbrou no contacto com o "Mestre"; e, por outro, a "biografia" que Fuegi publicou em 1994 e que, a pretexto de condenar o machismo de Brecht - que teria vampirizado intelectualmente as mulheres que com ele trabalharam deu motivos para um protesto indignado por parte de feministas que, neste caso, dificilmente aceitavam a menorização implícita num perfil de mulher tão cordatamente explorável. Outra voz, também americana, que se insurgiu contra os termos da putativa "biografia" de Brecht foi Fredric Jameson, autor do célebre estudo sobre a pósmodernidade (1991), e que recentemente lançou um livro sedutor e de inequivoco brilho argumentativo sobre o dramaturgo - Brecht and Method - que reelabora a leitura da sua obra, reconduzindo-a ao coração da dialéctica, e interrogando a "doutrina", o "gestus" e os "provérbios", em torno da curiosa arquitectura modernista presente em MeTi, ou o livro das reviravoltas (1965).
Por cá e neste início de século é de assinalar o notável empreendimento das Edições Cotovia de iniciar a publicação das obras completas (de que José Miranda Justo deu já notícia nesta revista ${ }^{5}$ e as encenações que, a meio da primeira década, e ainda que com opções diferenciadas, Luis Miguel Cintra e João Lourenço assinaram, respectivamente, de Um homem é um homem e Ópera de três vinténs.

Se a Cornucópia já levara à cena Terror e miséria no III Reich, em 1974, e Tambores na noite, em 1976, era ainda no contexto de uma direcção partilhada entre Luis Miguel Cintra e Jorge Silva Melo. Todavia, quando a companhia retoma um outro texto de Brecht, em 1983, já Silva Melo saíra da companhia, e tratava-se de incluir uma peça radiofónica - A travessia aérea do oceano num espectáculo (Oratória) que juntava a voz de Brecht a excertos de Vicente e de Goethe para interrogar um difuso, mas aflitivo - mal de viver que atravessava, não apenas o país em geral (em termos políticos e culturais), mas também o coração dos que por ali iam fazendo teatro. Mas ainda que não presente em voz própria, a verdade é que "herdeiros" vários da prática brechtiana foram ganhando forma e vida no espaço do Bairro Alto, como foi o caso de Edward Bond e de Heiner Müller, em repetidas visitações.

E veio, então, justamente agora o regresso a Brecht ele próprio. Depois de um ciclo de reflexão sobre o poder, em 2003 (que incluiu peças de Shakespeare, Calderón e Heiner Müller),a companhia fez, em 2004, uma curta visitação à alma romântica, na escrita de Heinrich von Kleist, e compôs duas admiráveis construções teatrais sobre clássicos portugueses referidos à comédia: Filodemo, de Luís de Camões, e Esopaida, ou A vida de Esopo, de António José da Silva. Cumpria-se, desta forma, e em continuidade, um caminho que acolhe a perspectiva critica relativamente à sociedade e aos seus mecanismos, mas simultaneamente arrisca a confrontação com grandes textos. E será na sequência desta intensa convergência de valores e exigências que se percebe a "explosão" do que já se chamou "o continente" Brecht, dando origem à verdadeira obra-prima que foi o espectáculo Um homem é um homem: A transformação do estivador Galy Gay no acampamento de Kilkoa no ano de mil novecentos e vinte e cinco ${ }^{6}$, e que integrava ainda o entremez, que Brecht incluíra logo na primeira versão da peça publicada em 1927, A cria de elefante, ou Tudo se pode provar.

Das versões diferentes da peça que Brecht foi escrevendo desde 1926, Luis Miguel Cintra optou pela mais longa, de 1953, aquela que de forma mais explicitamente crítica expõe a transformação do estivador em soldado, até se tornar uma verdadeira máquina de

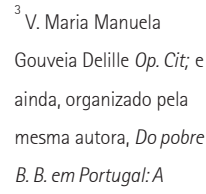
Estudos Germanisticos, 1998.

${ }^{4}$ Aconselha-se uma visita ao sitio do Centro de Estudos de Teatro (www.fl.ul.pt/centroestudos-teatro.htm) para a consulta da CETbase. A forma mais imediata de aceder a todas as encenações feitas (ou apresentadas) em Portugal a partir de obras de Brecht é procurar no menu inicial não a entidade

"espectáculos", que é a que automaticamente o menu oferece, mas a de "pessoas", inscrevendo-se ai o nome de Brecht.

5 José Miranda Justo, "A 'distância' ao nosso alcance: Teatro 1e 2, de Brecht", in Sinais de cena, n. 3 , Junho de 2005, pp. 115-118.

${ }^{6}$ Para além das apresentações estrangeiras (do grupo Jácara, em 1978, e da Comédie de Genève, dirigida por Benno Besson, em 1988), esta peça merecera já duas encenações em Portugal: de João Mota, para a Comuna, com o título Homem morto, homem posto (7 de Dezembro de 1978), sobre tradução de Fiama Hasse Pais Brandão e de Luis Varela, para o Cendrev, com o título Homem por homem $(6 \mathrm{de}$ 
Um homem é um homem

de Bertolt Brecht, enc. Luis Miguel Cintra,

Teatro da Cornucópia, 2005 (Duarte Guimarães e Nuno Melo, no elefante;

Dinarte Branco, Henrique Cardador, Maria João Luis, João Lizardo e Ricardo Aibéo), fot. Luis Santos.

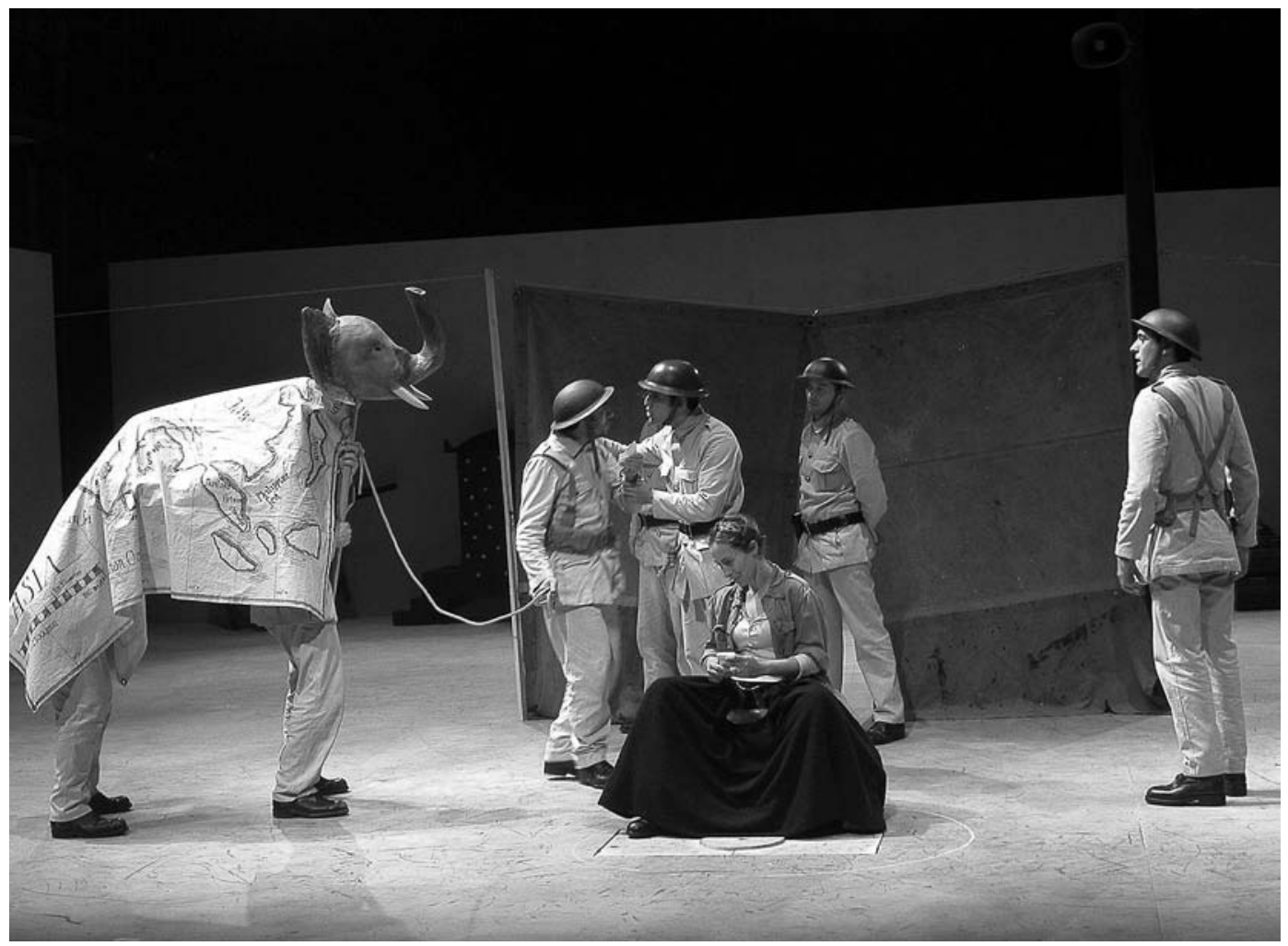

guerra, capaz de, em cima de um canhão, disparar sobre uma cidade inteira onde se tinham refugiado mulheres e crianças. Nesta versão é ainda possivel ver o ensandecimento do sargento, depois de se transformar em civil, atentando contra a sua virilidade, num assomo entre a demencial regressão infantilizada e a condição de boneco articulado (porque depois da alienação "militarista", perder esse estatuto é esvaziar-se por completo).

A questão da identidade individual, a sua inscrição num colectivo e a alienação são motivos centrais desta parábola. Mas nela se enfeixam outras linhas temáticas da leitura da história: a guerra predadora', o imperialismo (excelente ideia de cantarem Rule Britannia!), bem como a sua razão invertida - a imigração -, visível na importância obsessiva conferida ao passaporte. E duas outras formas, ainda que de sinal diferente, de "desumanização" são ainda expostas: a religião e o comércio. Nesta última prova-se que o que se vende não precisa de ter qualquer sentido ou valor, desde que alguém o queira comprar, legitimando a sua condição de mercadoria e privilegiando na relação entre as pessoas o cash nexus, ou seja a troca pelo dinheiro. Em ambas as práticas - religiosa e mercantil ,- o megafone artesanal servirá o discurso mercadejador e apologético, como se de uma feira se tratasse.

A cenografia de Cristina Reis representou um diálogo subtil entre as suas próprias formas de investir a cena e os "preceitos" que, em 1931, numa encenação desta peça em Berlim, Brecht inaugurava, de forma radical e modernista, como sendo o modo "épico" de representação. 0 palco elevado do Bairro Alto procurava "molduras" externas e internas: à esquerda, escadas; à direita, uma rampa; no espaço entre a bancada dos espectadores e o palco, um piano e uma "bananeira" perto das escadas; a toda a largura, entre escadas e rampa, sacos no chão (alguns deles serão mais tarde trazidos à cena para apoiar o canhão). Estes elementos asseguram a distância, mas, paradoxalmente também, a ligação entre cena e plateia. Mas outros enquadramentos surgiam ainda: delimitavase por dentro o palco com três paredes amareladas suficientemente baixas para se deixar ver a urdidura, e em cada uma delas indicava-se um espaço diferente: ao fundo, sinalizava-se o acampamento, com as

metralhadoras, os capacetes e o canhão; à direita, o lugar da cantina, onde se colocarão balcão, mesas e cadeiras e onde, pendurada na parede, está uma cabeça de elefante; à esquerda, uma pintura muito sumária - sobre a parede - de linhas geométricas (com pequenas saliências para permitir escalar), evoca um pagode - sem nada de concreto que remeta para isso, mas permitindo a divertidissima cena do assalto - e os dois adereços de cena indispensáveis para esconder um dos soldados: o palanquim e o sacrário. Mais central na cena está um poste altíssimo onde estará fixado um candeeiro e um altifalante (/sirene). E há ainda as cortinas: as que servirão para improvisar uma tenda para a cantina (que se colocarão à direita do palco de frente para a plateia) e, mais tarde, ao centro da cena, a meia altura, a cortina - vermelha - que servirá para o entremez.

Apesar da centralidade deste vermelho - tão icónico na representação do teatro - e da sua ocorrência também nas bandas - com escritos ideográficos - que irão ladear o sacrário, a paleta cromática dominante no espectáculo era sobretudo feita de castanhos, amarelos, beges e sépia. E a sua visibilidade maior esteve nas fardas dos oito soldados - entre o bege e o amarelo-torrado, como era a do exército colonial britânico -, destacando-se quatro deles (os que compunham a secção de metralhadora) com cara pintada de branco e lábios escuros (evocando porventura o cinema mudo, de Keaton ou Chaplin). Estes dois aspectos - uma economia de contrastes e uma hábil, mas leve, sinalização de "fingimento" - pautam uma encenação prodigiosa: a repartição entre o nivel da história 

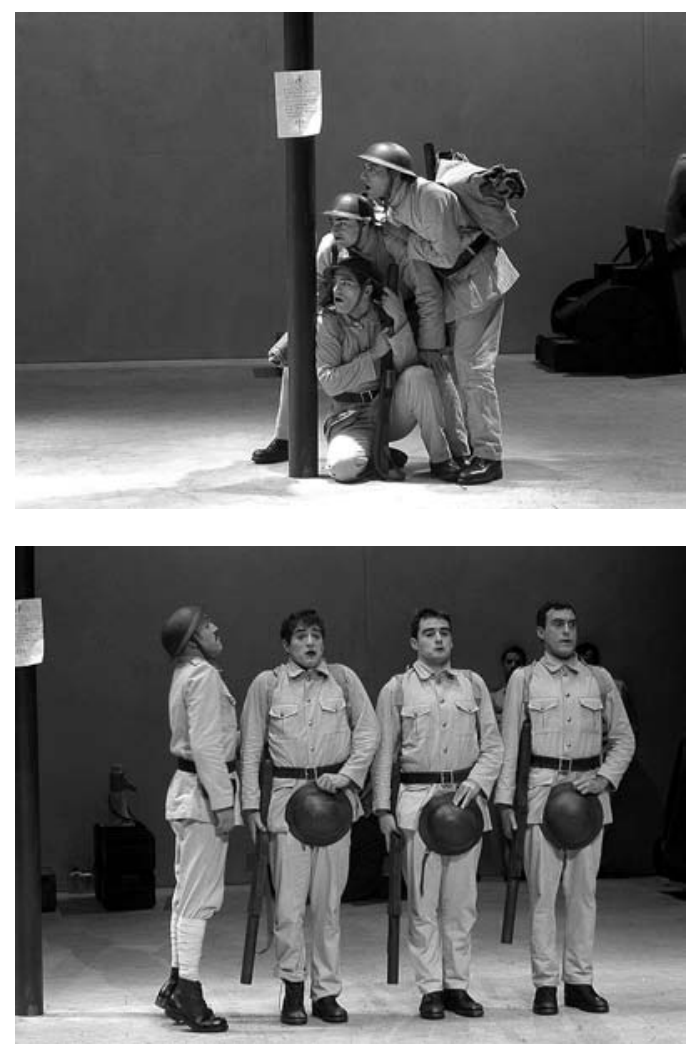

representada e os elementos que subtilmente indiciam a visão interrogadora que abre à ironia, ao sarcasmo, à exposição crua da mentira e da desumanização.

Esta inscrição maior nos procedimentos brechtianos revela a convergência de uma clarificação dramatúrgica de todas as pequenas acções, falas, gestos e atitudes, por um lado, e, por outro, uma consistente direcção de actores. Com um grau de notável coesão artística, algumas cenas surgem antológicas na composição de quadros de imagem fortíssima com pouco mais do que o puro trabalho de corpos em constelações performativas: o enterro de Galy Gay, o alinhamento dos actores deitados à boca de cena para figurar o comboio em andamento (simulando o desequilibrio com o corpo) e, de forma superlativa, o entremez - A cria de elefante - à boca de cena.

Furiosamente cómico, este teatro dentro do teatro, é forma de redistribuir alguns temas e imagens da peça, aproximando-as da derrisão fársica, ao mesmo tempo que joga na relação com a dupla plateia: não só os espectadores da Cornucópia, mas também os soldados que assistem à pecinha, bebendo, fumando, protestando e, para as apostas, frequentando o "bar" (atrás das bancadas

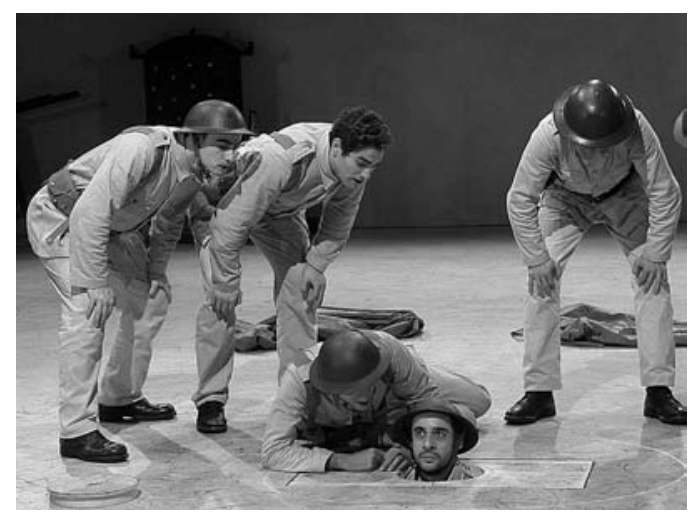

dos espectadores, no foyer quiçá, onde está o "verdadeiro" bar). Ao piano, Nuno Lopes (curiosa coincidência onomástica do actor e do pianista...) e a deliciosa construção e desconstrução do "julgamento" a que procede a "bananeira" (num trabalho magnífico de Nuno Lopes), com a prestimosa ajuda da lua (belíssima composição de Ricardo Aibéo) e da chorosa mãe (num eficiente registo cómico de Duarte Guimarães). Adoptando aspectos "amadorísticos" nos adereços (Cristina Reis na sua mais genuína criatividade artesanal), na gestualidade e no modo enfático de representar, o entremez é um momento de rara inteligência teatral e de assombrosa explosão cómica.

Ao longo do espectáculo é rigorosa a diferenciação de niveis de sentido e de teatralização: as armas são de madeira e "a fingir", e os disparos das pistolas, tiros das metralhadoras, bem como as explosões do canhão são feitos com a voz dos soldados (silvos, tantantan...). 0 mesmo procedimento ocorre com as garrafas de cerveja, de onde "bebem" e que estão manifestamente vazias. Porém, durante o entremez, os soldados que descem para perto da plateia estarão de facto a beber por canecas e a fumar, o que amplia ainda mais a distância entre a naturalidade destes e o registo burlesco do teatro dentro do teatro, com que dialogam. Entre estes opostos, o registo intermédio da "transformação" de Galy Gay em soldado, de Jeraiah Jip em deus, do sargento Fairchild em civil.

Dinarte Branco, vestindo um modesto fato cinzento de "operário" da estiva (não longe do que Brecht enverga em fotografias conhecidas), interpreta Galy Gay com um registo relativamente neutro, de serena desenvoltura, com momentos de variação visiveis: o ar malandro quando entra no bar (vagamente evocando alguns tiques de Raul Solnado em figura de soldado Schweyk), ou a aflição quando pensa que vai ser fuzilado. Mas sempre assumindo com alguma frieza (não isenta de intensidade) o jogo
Um homem é um homem, de Bertolt Brecht, enc. Luis Miguel Cintra, Teatro da Cornucópia, 2005 (de baixo para cima: Nuno Lopes, Duarte Guimarães e Ricardo Aibéo), fot. Luis Santos.

Um homeméum homem de Bertolt Brecht, enc. Luis Miguel Cintra, Teatro da Cornucópia, 2005 (Duarte Guimarães, Nuno Lopes, Ricardo Aibéo, Dinarte Branco e Henrique Cardador), fot. Luis Santos.

Um homem é um homem de Bertolt Brecht, enc. Luis Miguel Cintra, Teatro da Cornucópia, 2005 (José Wallenstein, Nuno Lopes,

Duarte Guimarães e Ricardo Aibéo), fot. Luis Santos. 
Um homem é um homem,

de Bertolt Brecht,

enc. Luis Miguel Cintra,

Teatro da Cornucópia,

2005 (Duarte Guimarães,

Nuno Lopes,

Dinarte Branco e

Ricardo Aibéo),

fot. Luis Santos.

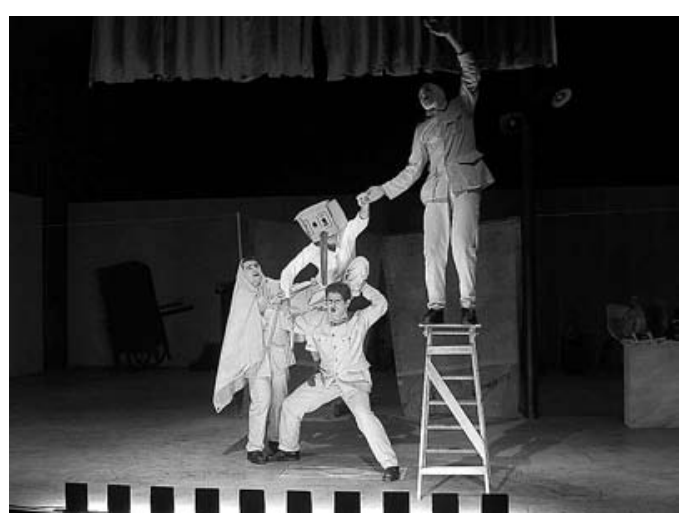

Um homem é um homem

de Bertolt Brecht,

enc. Luis Miguel Cintra

Teatro da Cornucópia 2005 (José Wallenstein

Duarte Guimarães,

Nuno Lopes,

Ricardo Aibéo,

Dinarte Branco e

Maria João Luis),

fot. Luis Santos.

interpretativo. Maria João Luis é uma cantineira expedita e de largo desenho em palco, que trabalha no fio entre a sedução e a rispidez, e com a mesma segurança canta e interpreta. José Wallenstein tem aqui uma composição admirável como Sargento Fairchild, e Pedro Lacerda, como Jeraiah Jip, explora o seu registo favorito, entre a lassidão indiferente, a mímica exagerada e a mecanicidade trôpega. De resto, o cómico é lugar aberto para uma diversidade de soluções, uma vez mais provando o acerto dramatúrgico na análise de cada cena e das várias possibilidades: os soldados chocando uns com os outros e batendo os capacetes, certas composições de conjunto a evocarem a banda desenhada (os irmãos Dalton ou os irmãos Metralha), a conversa dos soldados com Wang (num trabalho discreto e acertado de Luís Lima Barreto) quando imitam os que falam em voz alta e pausada com os estrangeiros esperando assim ser melhor compreendidos, ou, ainda, o equívoco do envolvimento físico dos dois soldados quando ficam presos na janela do pagode.

0 elemento musical, trazido pelo piano (com Nuno Lopes) e pelas canções, representou um belo trabalho de selecção de João Paulo Santos, que foi cumprido de forma apuradissima por todos, e resultou numa extraordinária combinação de melodias já conhecidas de Weill ("AlabamaSong", de Mahagonny, entre outras) e as que Paul Dessau escreveu para a última versão da peça. De resto, as explicações de João Paulo Santos inseridas no programa, o registo da colaboração dramatúrgica de Luís Varela e de Vera San Payo de Lemos (de quem se transcreve o texto que publicara no segundo volume das obras de Brecht na edição da Cotovia), a riqueza iconográfica e de informação do programa, tudo configura uma atitude de grande probidade intelectual e de extraordinária concitação do que se coloca como exigência cultural e artística a uma produção de teatro hoje. Ainda que - e é este o caso - essa exigência possa parecer excessiva, pela extensão de 3 h45 de espectáculo.

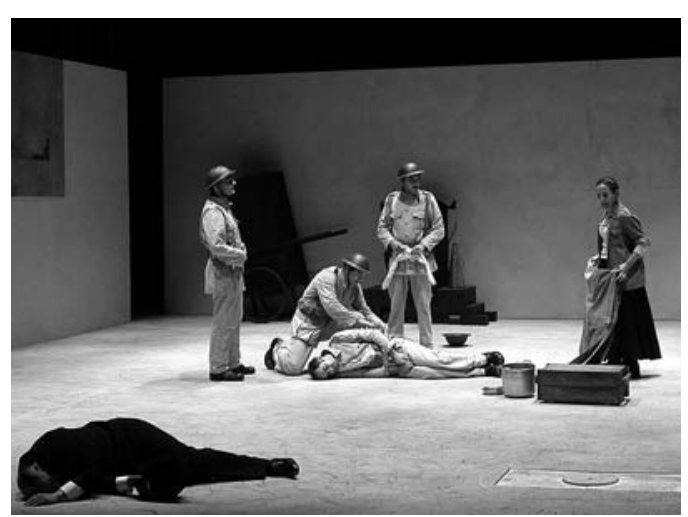

A exímia arquitectura deste espectáculo (em que, curiosamente, Luís Miguel Cintra não figura no elenco) prova ainda a superação que aqui se atingiu como forma de reinventar Brecht: numa apoteótica construção de sentido que revela o que ele tem ainda para nos dizer, a nós que "viemos depois dele" e com ele tanto aprendemos e nos divertimos.

\section{Referências bibliográficas}

FUEGI, John (1994), Brecht \& Co., New York, Grove. JAMESON, Fredric (1998), Brecht and Method, London \& New York, Verso (trad. brasileira: O método Brecht, trad. Maria Silvia Betti, revisão técnica Iná Camargo Costa, Petrópolis, Editora Vozes, 1999).

- - (1991) Postmodernism, Or, The Cultural Logic of Late Capitalism (1984), London, Verso.

STREHLER, Giorgio (1980), "Rencontre avec Brecht", in Un théâtre pour la vie [Per un teatro umano,1974], trad. do italiano de Emmanuelle Genevois, Paris, Fayard. 